\title{
Impact of bitumen composition on empirical properties
}

\author{
Eva Remišová ${ }^{1}$, and Michal Holý ${ }^{1, *}$ \\ ${ }^{1}$ University of Žilina, Department of Civil Engineering, Slovak Republic
}

\begin{abstract}
In recent years, there has been a further development of refining technology, which make it possible to better use of crude oil, which also has a major impact on the quality of bitumen. Most European refineries, of course, are processing, for reasons of the resale of petroleum products, especially petroleums suitable for the recovery of light and middle fractions. Therefore, light petroleums are required, with low yields of heavy fractions, which are highly economically and in dispositions efficient for processors on the petroleum market. Emphasis is placed on the sulfur content, the paraffin content is no longer the most important aspect. Less important from the perspective of the refinery is the content and the ratio of asphaltenes and maltenes. There is no doubt that we will have to change our view on petroleum products. Their availability will continue to decline, their price, on the other hand, is likely to grow in relation to falling supplies of resources. Therefore, the view of the bitumen must be changed. The most common way of production of PG bitumen is vacuum distillation, which is carried out in such a way that the vacuum distillation residue satisfies it's properties bitumen requirements for the relevant penetration.
\end{abstract}

\section{Introduction}

Currently, the manufacturers of asphalt mixtures [1,2] for development of quality uses their own technological processes for processing and newest technology and with their help ensure the required quality and application properties of the product. The required quality is achieved by ensuring the quality of input materials, coarse and fine aggregates and bitumen. The bitumen properties are verified by the prescribed tests which bitumen binder must satisfy and which are critical to the designation and definition of bitumen binders. Defined criteria of quality are defined in European standard and in Slovakia in catalogue sheets of bitumen. The datasheets determine the ways and use of bitumen binders for the production of mixtures for wearing courses, binder and base courses. The quality of bituminous binders used in the construction and maintenance of road surfaces is currently being assessed by empirical tests based on obtaining one value for specific boundary conditions that were designed around 100 years ago.

\footnotetext{
* Corresponding author: michal.holy@,fstav.uniza.sk
} 
The consistency at middle working temperatures (penetration), consistency at increase working temperatures (softening point) and consistency at lower temperatures (breaking point) are measured, regardless of the composition of the bitumen and the loads corresponding to the actual load on the road. The current state of the asphalt roads has led to new ways and approaches being sought to better describe the properties of bitumen binders and mixtures. One such approach is "performance related" approach. The system evaluates bitumen binders mainly after thermal stability tests (short-term RTFOT and longterm PAV) by functional tests, determining the stiffness modules using the dynamic rheometer (DSR) and the deflection beam rheometer (BBR). Bitumen binders are tested not in the state when they leave the refinery, but in the state when they leave the asphalt mixing plant, or after a certain period of exposure on the road in service. The primary emphasis is given to the characterization of rheological behavior that is viscoelastic behavior as a function of temperature and loading rate. The behavior of bitumen is primarily given chemical composition that is influenced source of petroleum and the processing method of bitumen.

According to petroleum chemist $[1,2]$ the bitumen is a residue of petroleum or a product of solvent extraction of petroleum. The configuration of the internal structure of a bitumen is largely determined by the chemical constitution of the molecular species present. Bitumen is a complex chemical mixture of molecules that are pre-dominantly hydrocarbons (carbon 82 to $88 \%$, hydrogen 8 to $11 \%$ ) with a small amount of structurally heterocyclic species and functional groups containing sulphur, nitrogen and oxygen atoms. Bitumen also contains minor quantities of metals such as vanadium, nickel, iron, magnesium and calcium, which occur in the form of inorganic salts and oxides or in porphyrine structures

The precise composition (elemental analysis) varies according to the source of the crude oil from which the bitumen originates, modification induced by semiblowing and blowing during manufacture and ageing in service. The chemical composition of bitumen is extremely complex. Thus, a complete analysis of bitumen (if it were possible) would produce such a large quantity of data that correlation with the empirical and rheological properties would be impractical, if not impossible. However, it is possible to separate bitumen into two chemical groups called asphaltenes and maltenes. The maltenes can be further subdivided into saturates, aromatics and resins (SARA). Based on the precipitation by lower alkali hydrocarbons, saturated compounds can be included together with aromatics and resins to the malten phase and asphaltenes to the asphalt phase. Asphaltenes can be considered as solid particles that thicken bitumen binders. They have dark brown sometimes a black color and higher molecular weight compared to resins. Asphaltenes can be characterized as aromatic and chlorinated solvents and also insoluble in low boiling alkanes. Resins can be described such as highly viscous liquids to solids of reddish-brown color. It can be stated that asphaltenes are the most important parts of asphalt binders which are dispersed in maltenes and that the resin has a significant effect on the stability of the asphaltenes which are dispersed in the resin. Bitumen from different sources of crude have different amounts of constituents and possibly different ability for reactions and each and every manifestation of change in the behavior of bitumen (such as aging etc.,) is due to the inter-conversion of one type of constituent to the other type.

The chemical properties determination allows to measure and undestand the various interactions among molecular species that contribute to behaviour of bitumen. Therefore the goal of a study was determine correlation of chemical and physical properties to explain the nature of bitumen. 


\section{Experimental program}

Within laboratory measurements there were studied the properties of binders for the production of asphalt mixes which are commonly used in practice for asphalt pavement construction - paving grade bitumen 50/70 (7 samples from different producers A1 - A7) and polymer modified bitumen PMB 45/80-75 (3 samples from different producers M1 M3).

Tests of basic properties were performed as penetration at $25{ }^{\circ} \mathrm{C}$ according EN 1426, softening point according EN 1427.
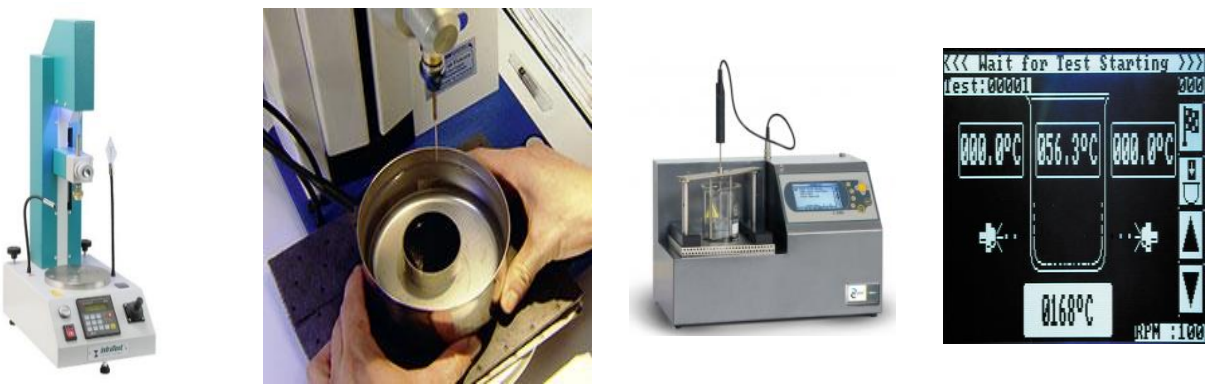

Fig. 1. Equipments for penetration and softening point test of bitumen

The content [3] of structurally similar compounds, SARA analysis (determination of the percentage of saturated hydrocarbons, aromatics, resins and asphaltenes) was carried out using the combined extraction method (according to STN 65 6073) and liquid chromatography. This requires special equipment and chemical agents (n-heptane, toluene, alumina 507C sorbent, silver nitrate modified silica gel) and the specialized laboratories. The apparatus for determining the asphaltenes content and group composition of maltenes is shown in Figure. To determine C, H, N, S content there was used Elementar Vario Cube with TCD detection. Test was performed by means of controlled sample combustion process at a temperature of 800 to $1000{ }^{\circ} \mathrm{C}$ and subsequent analysis of the flue gases by the detector. These analyses were carried out at the Institute of Oil and Alternative Fuels VŠCHT in Prague.
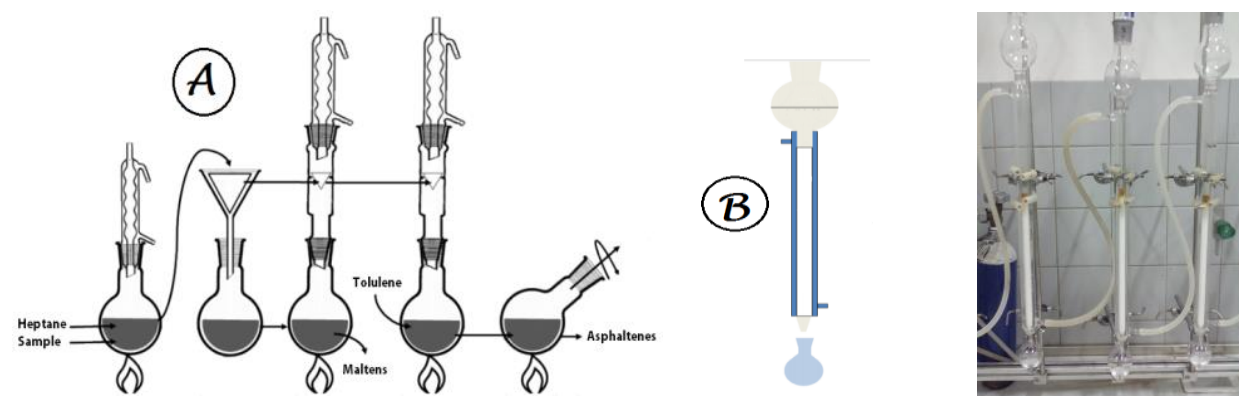

Fig. 2. a) Scheme of equipments for the determination of asphaltenes by extraction, b) Scheme of eguipments for determining the group composition of maltens.

\section{Results and analysis}

The values from the measurement of the group composition of bitumen respectively of the elementary composition are shown in Table 1 . The table shows the average composition of 
paving grade bitumen 50/70 (7 tested samples A1 - A7) and polymer modified bitumen 45/80-75 (3 tested samples M1 - M3).

From the results of the chemical composition, it can be stated that at the average values of the group composition is the greatest difference between PMB and PG in the Aromate content ( $\mathrm{PG}$ has a $+1.6 \%$ higher content of aromatics with compared to $\mathrm{PMB}$ ) and Asphaltenes (PMBs have a $+2 \%$ higher content of asphaltenes with compared to PG). From the elemental composition point of view, we can say that both types of bituminous binders have relatively the same Nitrogen and Hydrogen contents and differences can be observed for Carbon (PMB has a $+0.69 \%$ higher $\mathrm{C}$ content with compared to $\mathrm{PG}$ ) and Sulphur (PG has a $+0.72 \%$ higher $\mathrm{S}$ content with compared to $\mathrm{PMB}$ ) content.

Table 1. Average content of components in samples.

\begin{tabular}{|c|c|c|c|c|}
\hline \multicolumn{5}{|c|}{ Average content of components in samples (\%) } \\
\hline Type of bitumen & Saturates & Aromatics & Resins & Asphaltenes \\
\hline $50 / 70$ & 8.63 & 35.48 & 42.61 & 13.28 \\
\hline PMB 45/80-75 & 8.59 & 33.88 & 42.25 & 15.28 \\
\hline Type of bitumen & $\mathbf{C}$ & $\mathbf{H}$ & $\mathbf{N}$ & S \\
\hline $50 / 70$ & 84.31 & 10.18 & 0.54 & 4.38 \\
\hline PMB 45/80-75 & 85.00 & 10.39 & 0.54 & 3.66 \\
\hline
\end{tabular}
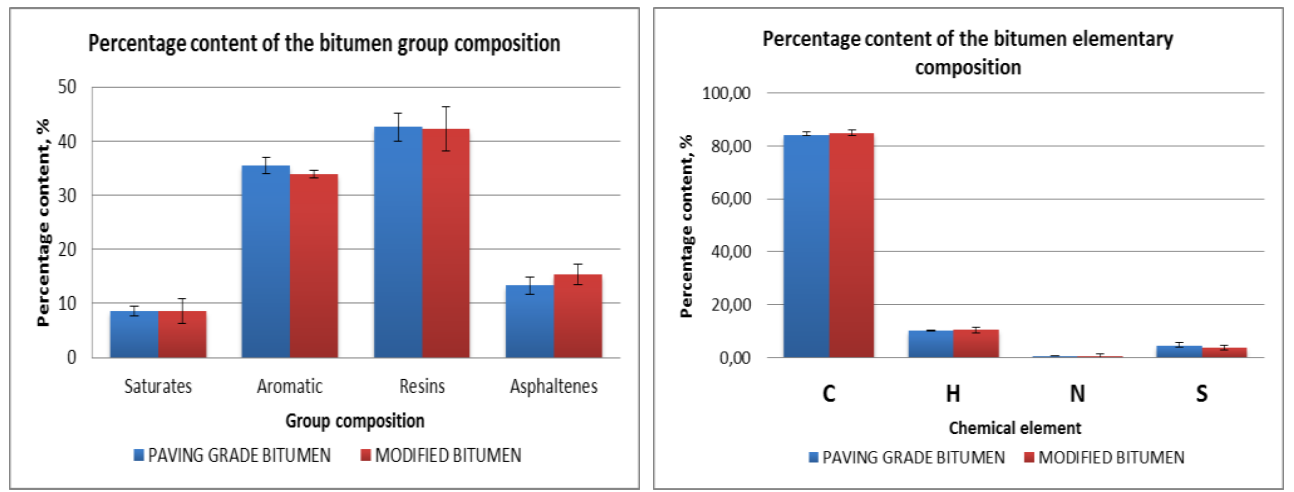

Fig. 3. Percentage content of the bitumen group composition (left), Percentage content of the bitumen elementary composition.

If we compare the average achieved results of the elementary composition of bitumen which are commonly used in Slovakia (from different producers OMV, Total, Mol, Orlen) and compare them with bitumen from the Ural cruide source (Russia) and Canada crude source, we can see that the elementary composition of bitumen used in tests is similar. The greatest difference can be observed with oxygen content, where tested bitumen have by $50 \%$ lower content. By content a Carbon and Hydrogen, tested bitumen are more similar to Ural bitumen but the sulfur content is getting closer to bitumen from Canada. 
Table 2. The comparision of the average achieved results of the elementary composition of bitumen which are commonly used in Slovakia with bitumen from the Ural cruide source (Russia) and Canada crude source.

\begin{tabular}{|c|c|c|c|c|c|}
\hline \multicolumn{7}{|c|}{ Elemental composition (\%) } \\
\hline Source & $\mathrm{C}$ & $\mathrm{H}$ & $\mathrm{N}$ & $\mathrm{O}$ & $\mathrm{S}$ \\
\hline Bitumen - Ural cruide oil & 85.20 & 10.30 & 0.58 & 1.25 & 2.67 \\
\hline Bitumen - Cold Kanada cruide oil & 83.17 & 10.28 & 0.45 & 1.33 & 4.77 \\
\hline Tested bitumens 50/70 & 84.31 & 10.17 & 0.54 & 0.58 & 4.38 \\
\hline Tested bitumens PMB 45/80-75 & 84.99 & 10.38 & 0.53 & 0.41 & 3.66 \\
\hline
\end{tabular}

The next step was to perform basic empirical tests (penetration and softening point) for paving grade bitumen and polymer modified bitumen. Despite the same grade of bitumen, we can observe a relatively high variability of results (Figure 4). In the case of paving grade bitumen, the range of softening points is from $48{ }^{\circ} \mathrm{C}$ to $51{ }^{\circ} \mathrm{C}$ and range of penetration is from 53 to $75.90 .1 \mathrm{~mm}$. In the case of polymer modified bitumen, the range of softening points is from $75.4{ }^{\circ} \mathrm{C}$ to $80.8{ }^{\circ} \mathrm{C}$ and range of penetration is from 54.6 to $74.30 .1 \mathrm{~mm}$.

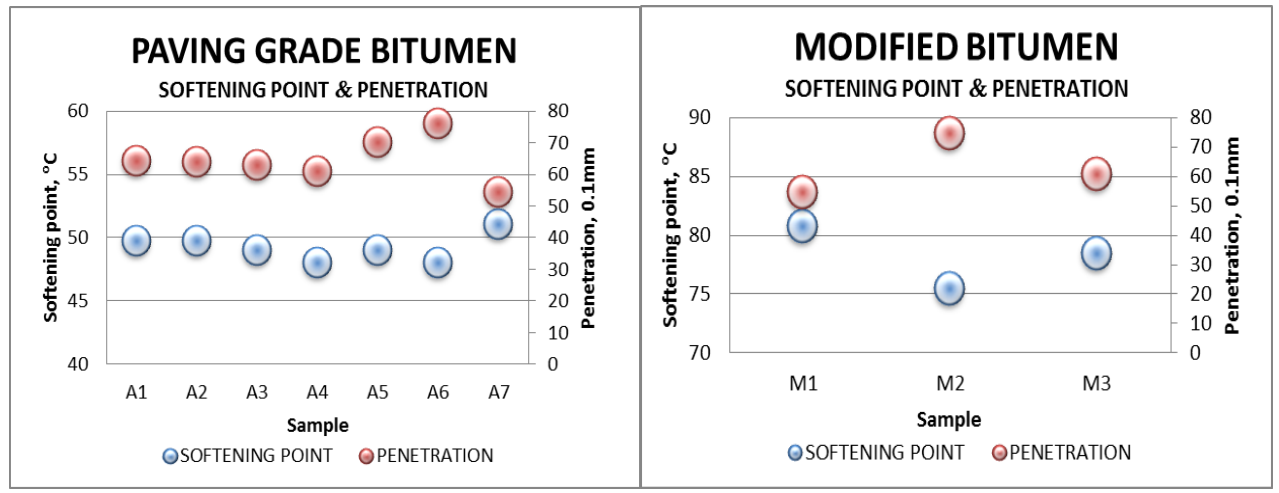

Fig. 4. Results from the measurement of the softening point and penetration for paving grade bitumen (left) and modified bitumen (right).

The last step was to find out whether there is a relationship between elementary and / group composition of bitumen and empirical tests represented by penetration and softening point, and if there is a relationship and if the relationship exists, to what extent the bitumen composition can affect the properties of the of bitumen. 

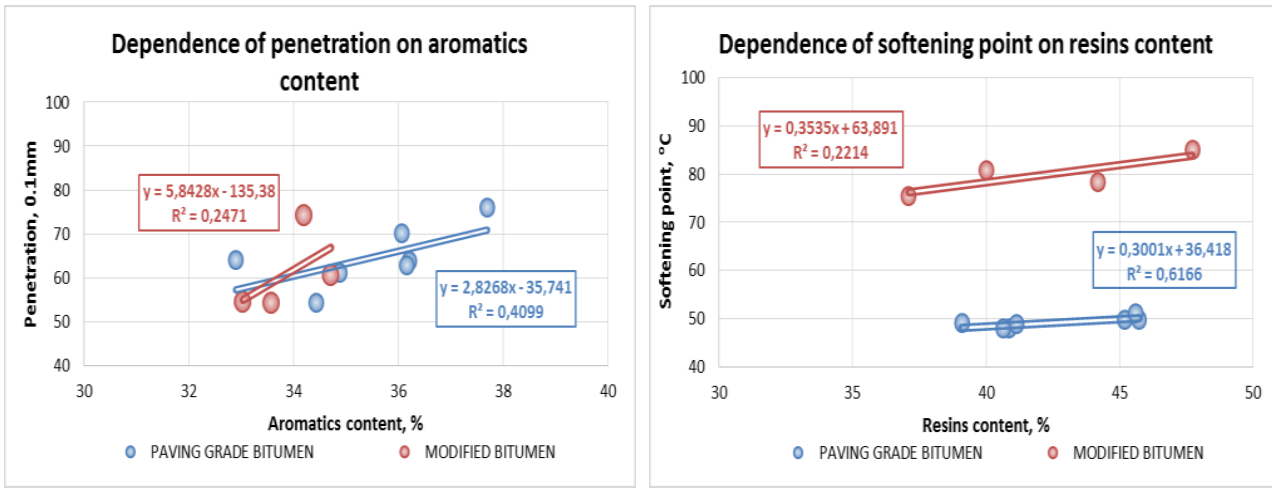

Fig. 5. Dependence of penetration on aromatics content (left), dependence of softening point on resins content (right).

In terms of group composition, aromatics have the greatest impact on penetration. From Figure 5 dependence of penetration on aromatics, we can see, the higher the aromatic content causes that the bitumen have a higher values of penetration and that's why the bitumen become a softer. Regression dependence of aromatic and penetration in Figure 5 (linear) shows average values of determination coefficient $\mathrm{R}^{2}$ for paving grade bitumen (0.4099) and low values of determination coefficient $R^{2}$ for modified bitumen $(0.2571)$, what means correlation in range of 0.64 (paving grade bitumen) to 0.48 (polymer modified bitumen). These values of correlation give assumption that between penetration and aromatic some dependence exist (at least for paving grade bitumen).

In the case of softening point we can see a significant effect of the resin. For both types of bitumen binders we can observe, the higher content of resin will causes that values of the softening point will be higher too. Regression dependence of resin and softening point in Figure 5 (linear) shows an average values of determination coefficient 0.6166 for paving grade bitumen and lower values of determination coefficient 0.2214 for modified bitumen, what means correlation in range of 0.785 (paving grade bitumen) to 0.469 (polymer modified bitumen). These values of correlation give assumption that between softening point and resin some dependence exist ( again at least for paving grade bitumen).
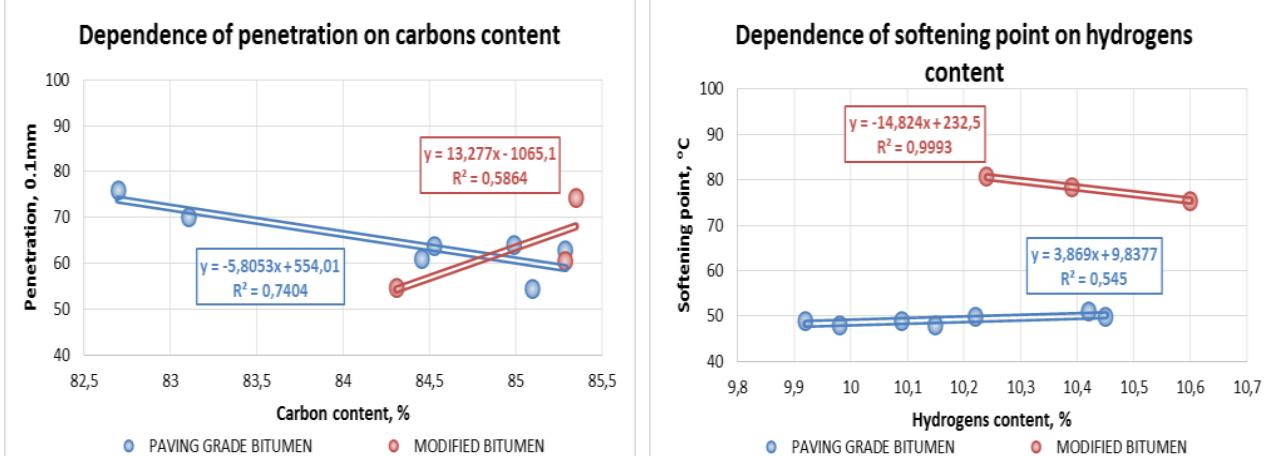

Fig. 6. Dependence of penetration on carbons content (left), dependence of softening point on hydrogens content (right).

While in the case of group composition and empirical tests the dependence was relatively the same shape for both types of asphalt for the elementary composition, can be seen some small the differences. From an elementary point of view, a carbon content has 
the most influence to penetration however, while for paving grade bitumen, a higher carbon content also means higher penetration, in modified asphalts, a higher carbon content will cause a reduction of penetration. Regression dependence of resin and softening point in Figure 6 (linear) shows a higher values of determination coefficient $\mathrm{R}^{2}$ for paving grade bitumen (0.7416) and average values of determination coefficient $\mathrm{R}^{2}$ for modified bitumen (0.5864), what means correlation in range of 0.86 (paving grade bitumen) to 0.76 (polymer modified bitumen). The results indicate that higher values of correlation in dependence between carbon and penetration were reached and therefore we can state that there is also dependence but it should be noted that this correlation was only issued for three PMB samples, and it is assumed that at a larger sample it will be reduced The content of hydrogen significantly influences the softening point. In case of paving grade bitumen we can state that the higher the hydrogen content causes the higher values of the softening point. With modified bitumen we see that higher hydrogen content causes a decrease in the softening point. Regression dependence of resin and softening point in Figure 6 (linear) shows a higher values of determination coefficient $R^{2}$ for paving grade bitumen $(0.7545)$ and very hight values of determination coefficient $\mathrm{R}^{2}$ for modified bitumen (0.999), what means correlation in range of 0.73 (paving grade bitumen) to 0.999 (polymer modified bitumen - again, here should be noted that this correlation was only issued for three PMB samples, and it is assumed that at a larger sample it will be reduced). The results indicate that higher values of correlation in dependence between hydrogen and softening point were reached and therefore we can state that there is also dependence.

\section{Conclusions}

In recent years, there has been a further development of refining technology, which make it possible to better use of crude oil, which also has a major impact on the quality of bitumen. Bitumen from different sources of crude have different amounts of constituents and possibly different ability for reactions and each and every manifestation of change in the behavior of bitumen (such as aging etc.,) is due to the inter-conversion of one type of constituent to the other type.

The chemical properties determination allows to measure and undestand the various interactions among molecular species that contribute to behaviour of bitumen. Therefore the goal of a study was determine correlation of chemical and physical properties to explain the nature of bitumen. Studies of chemical and elemental composition of bitumen binders have been performed. From the results of the chemical composition, it can be stated that at the average values of the group composition is the greatest difference between PMB and PG bitumen in the Aromate content (PG has a $+1.6 \%$ higher content of aromatics with compared to PMB) and Asphaltenes (PMBs have a $+2 \%$ higher content of asphaltenes with compared to PG). From the elemental composition point of view, we can say that both types of bituminous binders have relatively the same Nitrogen and Hydrogen contents and differences can be observed for Carbon (PMB has a $+0.69 \%$ higher C content with compared to $\mathrm{PG}$ ) and Sulphur ( $\mathrm{PG}$ has a $+0.72 \%$ higher $\mathrm{S}$ content with compared to $\mathrm{PMB}$ ) content.

In the next steps, basic empirical tests were performed, such as penetration and softening point for paving grade bitumen and polymer modified bitumen with the aim of finding dependence between composition and physical properties. Intermediate dependencies have been discovered between binder penetration and aromatics content (correlation in range of $0.64 \mathrm{PG}$ bitumen to $0.48 \mathrm{PMB}$ bitumen), softening point and resins content (correlation in range of 0.785 PG bitumen to 0.469 PMB bitumen), penetration and carbon content (correlation in range of $0.86 \mathrm{PG}$ bitumen to $0.76 \mathrm{PMB}$ bitumen), softening point and hydrogens content (correlation in range of 0.73 PG bitumen to 0.999 PMB 
bitumen). However, it should be noted that this correlation was only issued for three PMB samples. These results give assumption for further research.

The authors are grateful for the financial support from the research project VEGA 1/0300/17 Research of performance related and rheological properties of bituminous binders.

\section{References}

1. J.F. Branthaver et al., SHRP-A-368 Binder Characterization and Evaluation. Vol. 2 : Chemistry. ISBN 0-309-05620-9. (1993)

2. J. Read, D. Whiteoak, The Shell Bitumen Handbook, 4th edition. Thomas Telford, London. ISBN 0-7277-3220-X. (2003)

3. Team of autors, Instructions for laboratory work of the Institute of Oil and Alternative Fuels, University of chemistry and technology Prague, Avaible from: http://utrap.vscht.cz/files/uzel/0014520/0004 8zu8sCw_pVKhoChfIScxKb8osSS_K O_wWqDA4YXJqQqHdxWXJJaVKhgZmgIA.pdf?redirected $>$ (2017)

4. EN 1426 Bitumen and bituminous binders. Determination of needle penetration. (August 2010).

5. EN 1427 Bitumen and bituminous binders. Determination of the softening point. Ring and Ball method. (August 2010)

6. STN 656073 Petroleum products. Determination of asphaltene with n-heptane (in Slovak). (1973) 